\title{
Clinical analysis of the treatment of patients with wasp stings.
}

\author{
Ting Wang*, Hong BW \\ Department of Nephrology, the Third Hospital of Mian Yang, Mian Yang, Si Chuan, PR China
}

\begin{abstract}
Objective: To summarize the clinical diagnosis and treatment of wasp stings.

Methods: A retrospective study of 158 patients with wasp stings treated at our hospital from April to November 2014 was performed, and the clinical data of each patient, analysis of clinical manifestations, treatment and prognosis were determined.

Results: 145 patients recovered and 13 patients died. The average duration of hospitalization was 6.8 days.

Conclusion: Wasp stings can cause local reactions, and can even lead to multiple organ damage. Early treatment can improve the cure rate.
\end{abstract}

Keywords: Wasp stings, Multiple organ damage, Treatment.

Accepted on November 24, 2017

\section{Introduction}

Wasp venom is a biological toxin. Wasp stings can cause a variety of symptoms such as local reactions including swelling, redness, heat and pain, and severe wasp venom absorption, can cause fever, dizziness, coma, failure of the heart, liver, kidneys, and even death $[1,2]$. We performed a retrospective study of 158 patients with wasp stings treated at our hospital from April to November 2014.

\section{Materials and Methods}

\section{Clinical data}

A total of 158 patients, 85 male, 73 female, aged 12-84 years with an average age of 52.9 years were included in the study. The injured part in 3 or more, up to more than 100. Time to treatment ranged from $1 \mathrm{~h}$ to 1 day (average $6.5 \mathrm{~h}$ ). The patients had no preexisting health conditions, such as liver, kidney, heart and blood system diseases. The sting site was mainly in the head, neck, trunk and limbs. All patients had a local inflammatory reaction, and dizziness, nausea, and vomiting were observed in 124 patients (78.5\%). Thirty-four patients $(21.5 \%)$ presented with angioedema and urticaria. Liver injury was found in 88 patients (55.7\%) and 100 patients $(62.9 \%)$ had cardiac muscle injury. Coagulopathy or hemolysis was found in 98 patients $(62.1 \%)$ and 77 patients $(48.7 \%)$ presented with renal injury (on routine urine examination or renal anomalies). Gross hematuria or dark-red colored urine was detected in $26(16.5 \%)$ of cases and 13 $(8.2 \%)$ patients presented with oliguria or anuria. Acute abdomen (acute pancreatitis, acute cholecystitis, acute peritonitis) was found in 14 patients $(8.9 \%)$, and 2 patients $(1.3 \%)$ had upper gastrointestinal tract hemorrhage.
Six patients $(3.8 \%)$ had nervous system injury, and 14 patients $(8.9 \%)$ developed acute respiratory failure. Dysfunction of two or more organs was identified in 103 patients $(65.2 \%)$. Length of hospital stay was 6.8 days (1.0-67.0 days) (Table 1).

Table 1. Clinical symptoms in the included patients $(n=158)$.

\begin{tabular}{ll}
\hline Clinical symptoms & Values, $\mathbf{n}(\%)$ \\
\hline Clinical manifestations & $124(78.5 \%)$ \\
\hline Angioedema and urticaria & $34(21.5 \%)$ \\
\hline Liver injury & $88(55.7 \%)$ \\
\hline Cardiac muscle injury & $100(62.9 \%)$ \\
\hline Renal injury & $77(48.7 \%)$ \\
\hline Gross hematuria or dark-red colored urine & $26(16.5 \%)$ \\
\hline Oliguria or anuria & $13(8.2 \%)$ \\
\hline Acute abdomen & $14(8.9 \%)$ \\
\hline Gastrointestinal tract hemorrhage & $2(1.3 \%)$ \\
\hline Nervous system injury & $6(3.8 \%)$ \\
\hline Acute respiratory failure & $14(8.9 \%)$ \\
\hline Multiple organ dysfunction & $103(65.2 \%)$ \\
\hline
\end{tabular}

\section{Laboratory examinations}

Laboratory examinations identified the following parameters: white blood cell $(\mathrm{WBC})(7.8-55.2) \times 10^{9} / \mathrm{L}$, receptor protein (CRP) $5-158.4 \mathrm{mg} / \mathrm{L}$, activated partial thromboplastin time (APTT) 26.4-234.1 s , creatinine (Cr) 56.4-1245.6 $\mu \mathrm{mol} / \mathrm{L}$, urea nitrogen (BUN) 5.56-53.4 $\mathrm{mmol} / \mathrm{L}$, alanine aminotransferase (ALT) 18-5034 U/L, total bilirubin 
(TBIL) 12.8-250.1 $\mu \mathrm{mol} / \mathrm{L}$, creatine kinase (CK) 172-95732 $\mathrm{U} / \mathrm{L}$, creatine kinase isoenzyme (CKMB) 20-1740 U/L, lactate dehydrogenase (LDH) 125-14685 U/L, and lactic acid (Lac) 0.9-15.2 $\mathrm{mmol} / \mathrm{L}$ (Table 2).

Table 2. Laboratory indices in the included patients.

\begin{tabular}{ll}
\hline Laboratory indicators & Values \\
\hline WBC $\left(10^{9} / \mathrm{L}\right)$ & $7.8-55.2$ \\
\hline $\mathrm{CRP}(\mathrm{mg} / \mathrm{L})$ & $5-158.4$ \\
\hline $\mathrm{APTT}(\mathrm{s})$ & $26.4-234.1$ \\
\hline $\mathrm{Cr}(\mu \mathrm{mol} / \mathrm{L})$ & $56.4-1245.6$ \\
\hline $\mathrm{BUN}(\mathrm{mmol} / \mathrm{L})$ & $5.56-53.4$ \\
\hline $\mathrm{ALT}(\mathrm{U} / \mathrm{L})$ & $18-5034$ \\
\hline $\mathrm{TBIL}(\mu \mathrm{mol} / \mathrm{L})$ & $12.8-250.1$ \\
\hline $\mathrm{CK}(\mathrm{U} / \mathrm{L})$ & $172-95732$ \\
\hline $\mathrm{CKMB}(\mathrm{U} / \mathrm{L})$ & $20-1740$ \\
\hline $\mathrm{LDH}(\mathrm{U} / \mathrm{L})$ & $125-14685$ \\
\hline $\mathrm{Lac}(\mathrm{mmol} / \mathrm{L})$ & $0.9-15.2$ \\
\hline
\end{tabular}

\section{Treatment}

Local treatment: The sting was removed if possible. After rinsing and iodophor disinfection, a Ji Desheng she tablet was applied to the wound.

Systemic comprehensive treatment: (1) All patients received intravenous methylprednisolone $80-1000 \mathrm{mg} /$ day to reduce inflammation, and the dosage was then gradually reduced. (2) Intravenous glutathione and a large dose of vitamin $\mathrm{C}$ were administered to inhibit the oxidative stress reaction. (3) Antibiotics were selected to fight infection based on reduced side effects in the liver and kidneys. (4) The fluid balance, electrolytes and acid-base were maintained. (5) Symptomatic treatment: Medication was given to protect the liver and kidneys, improve cerebral metabolism, and prevent digestive tract hemorrhage. Blood transfusion was administered to the patients as necessary. Patients with acute respiratory failure (ACF) were given oxygen, and a tracheal cannula combined with mechanical ventilation as necessary.

Blood purification Patients with hematuria or urine the color of soy sauce received plasmapheresis combined with continuous renal replacement therapy (CRRT). Plasmapheresis was undertaken 1-3 times with $2000 \mathrm{~mL}$ plasma each time. CRRT was carried out for $12-82 \mathrm{~h}$. Other patients received intermittent blood purification treatment (IHD) combined with hemoperfusion (HP), at a time of 2-4 h for 2-4 days. Patients with ARF received IHD or hemodiafiltration (HDF) 2-3 times per week, for $4 \mathrm{~h}$ each time. Blood purification treatment was stopped when the patient entered the polyuria period and serum creatinine was below $400 \mu \mathrm{mol} / \mathrm{L}$.

\section{Results}

Twenty-nine patients with mild symptoms received intravenous methylprednisolone $80 \mathrm{mg} /$ day and were discharged from hospital after 3-7 days. Two patients with upper gastrointestinal bleeding were successfully treated with antihemorrhage drugs. Fourteen patients with symptoms of acute abdomen received specialist symptomatic treatment and achieved complete remission. Thirty-four patients with allergic rash were treated with anti-allergic agents, such as loratadine, chlorphenamine and calcium gluconate. Of 103 patients with dysfunction of two or more organs, 13 died including 11 due to acute respiratory distress syndrome (ARDS), 1 due to a large area of cerebral infarction with hemorrhage, 1 due to emergency malignant arrhythmia and 1 due to heart failure as a result of refusing hemodialysis.

\section{Discussion}

Wasp stings occur world-wide, especially in developing countries due to swarm attacks [3-6]. Wasp venom consists of a mixture of biologically active substances e.g. enzymes (phospholipases, hyaluronidase), peptides (melittin, apamin, mastoparans, bombolitins) and low-molecular-weight compounds (biogenic amines, acetylcholine, carbohydrates, lipids, free amino acids) [7]. Melittin is the main pathogenic factor, containing a neurotoxin, hemolytic toxin and mast cell degranulation compounds. Following a sting, wasp venom can induce multi-organ injury, including renal [8,9], nervous system [10-12], cardiac [13], liver [14,15], and respiratory system [16-18] injury, due to its complexity. Wasp venom not only causes direct damage to human organs and tissues, but also aggravates the condition via the allergic reaction and inflammatory reaction [19].

In our patients, prognosis was related to age, location and number of wasp stings, health status, the inflammatory reaction, distribution and treatment [20]. Greater levels of leukocytes and CRP, and the presence of ARDS and nervous system damage complicate the condition and indicate severe inflammation. In conclusion, treatment of wasp stings should be offered as early as possible, and should include local treatment in addition to appropriate treatments such as methylprednisolone, the correct mode of blood purification, and prevention of the systemic inflammatory response syndrome. Multiple organ dysfunction should be reduced in order to improve the prognosis of patients and reduce the mortality rate.

\section{References}

1. Fang XL. The effect of plasmapheresis on wasp sting patients. Chin J Blood Tran 2006; 19: 49.

2. Xie C, Xu S, Ding F, Xie M, Lv J, Yao J. Clinical features of severe wasp sting patients with dominantly toxic reaction: analysis of 1091 cases. PLoS ONE 2013; 8: e83164.

3. Pramanik S, Banerjee S. Wasp stings with multisystem dysfunction. Indian Pediatr 2007; 44: 788-790. 
4. Loh $\mathrm{HH}$, Tan $\mathrm{CH}$. Acute renal failure and posterior reversible encephalopathy syndrome following multiple wasp stings: a case report. Med J Malaysia 2012; 67: 133-135.

5. Bhatta N, Singh R, Sharma S, Sinnha A, Raja S. Acute renal failure following multiple wasp stings. Pediatr Nephrol 2005; 20: 1809-1810.

6. Zheng Liu, Xiang-Dong Li, Bo-Hui Guo. Acute interstitial nephritis, toxic hepatitis and toxic myocarditis following multiple Asian giant hornet stings in Shanxi Province, China. Environ Health Prev Med 2016; 21: 231-236.

7. Ciszowski K, Mietka-Ciszowska A. Hymenoptera stings. Praegl Lek 2007; 64: 282-289.

8. Vikrant S, Pandey D, Machhan P. Wasp envenomationinduced acute renal failure: a report of three eases. Nephrology 2005; 10: 548-552.

9. Vikrant S, Parashar A. Two cases of acute kidney injury due to multiple wasp stings. Wilderness Environ Med 2017; 28: 249-252.

10. Gal R, Libersat F. A wasp manipulates neuronal activity in the subesophageal ganglion to decrease the drive for walking in its cockroach prey. PLoS One 2010; 5: e10019.

11. Lin CJ, Wu CJ, Chen HH. Multiorgan failure following mass wasp stings. South Med J 2011; 104: 378-379.

12. Betten DP, Richardson WH, Tong TC. Massive honey bee envenomation-induced rhabdo- myolysis in an adolescent. Pediatrics 2006; 117: 231-235.

13. Cvetkovie-Matie D, Asanin M, Matig D. Acute myocardial infarction folloWing a hornet sting. Vojnosanit Pregl 2009; 66: 333-337.

14. Nittner-Marszalska M, Malolepszy J, Mlynarczewski A. Toxic reactions induced by humenoptera sting. Pol Arch Med Wewn 1998; 100: 252-256.
15. Tsai CL, Fang CC, Chen WJ, Dierberg K. Hornet stinginduced toxic hepatitis. Clin Toxicol 2005; 43: 127-128.

16. Franca FOS, Benvenutl LA, Fan HW. Severe and fatal mass attacks by "killer" bees ( Africanized honey bees Ap is Mellifera scutellata) in Brazil: clinicopathological studies with measurement of serum venom concentrations. Q J Med 1994; 87: 269-282.

17. Ma BY, Wei XQ, Dong FZ. A case report of ARDS induced by wasp sting. J Chin Phys 2008; 10: 143.

18. Kularatne K, Kannangare T, Jayasena A. Fatal acute pulmonary oedema and acute renal failure following multiple wasp/hornet (Vespa affinis) stings in Sri Lanka: two case reports. J Med Case Rep 2014; 8: 188.

19. Vidhate MR, Sharma P, Verma R. Bilateral cavernous sinus syndrome and bilateral cere bral infarcts: a rare combination after wasp sting. J Neurol Sci 2011; 301: 104-106.

20. Banovcin P, Havlicekova Z, Jesenak M. Severe quadriparesis caused by wasp sting. Turk J Pediatr 2009; 51: 485-488.

\section{*Correspondence to}

Ting Wang

Department of Nephrology

The Third Hospital of Mian Yang

PR China 